\title{
Cross-Sectional Study of the Characteristics of Reported Elder Self-Neglect in a Community-Dwelling Population: Findings from a Population-Based Cohort
}

\author{
Xin-Qi Donga ${ }^{\mathrm{a}}$ Melissa Simon ${ }^{\mathrm{b}}$ Denis Evans ${ }^{\mathrm{a}}$ \\ ${ }^{a}$ Department of Internal Medicine, Rush University Medical Center, and bepartment of Obstetrics and \\ Gynecology, Northwestern University Medical Center, Chicago, III., USA
}

\section{Key Words}

Self-neglect · Social network · Social engagement · Aging • Elderly $\cdot$ Cross-sectional study $\cdot$ Population-based study

\begin{abstract}
Background: Elder self-neglect is an important public health issue. However, little is known about the characteristics of self-neglect and its association with social factors among community-dwelling populations. Objectives: (1) To examine the sociodemographic, health-related and psychosocial characteristics of reported elder self-neglect; (2) to examine the association of social network and social engagement with reported self-neglect. Methods: Population-based study conducted from 1993 to 2005 of community-dwelling subjects $(n=9,056)$ participating in the Chicago Health and Aging Project (CHAP). Subsets of the CHAP subjects ( $n=1,812$ ) were identified for suspected self-neglect by the social services agency, which also assessed the severity. This reported group was compared with the unreported group in the CHAP across the sociodemographic, health-related and psychosocial variables. Logistical regressions were used to assess the association of social factors and self-neglect. Results: Older age, women, African-Amer-
\end{abstract}

icans, and those with lower education or lower income were more likely to be reported for self-neglect. Those reported for self-neglect were more likely to have lower levels of cognitive and physical function, nutritional status, psychosocial function and a higher number of medical comorbidities. After adjusting for confounders, lower levels of social network and social engagement were significantly associated with an increased risk of reported self-neglect. Among the reported cases of self-neglect, the study found increased trends of older age, women, African-American, lower income, lower cognitive and physical function, lower social engagement and a higher number of chronic medical conditions with self-neglect severity. Conclusion: Reported selfneglect elders have multiple sociodemographic, healthrelated and psychosocial characteristics that are different than elders not reported. Lower levels of social network and social engagement were associated with increased risk of self-neglect.

Copyright $\odot 2009$ S. Karger AG, Basel

X.-Q.D. had full access to all of the data in the study and takes responsibility for the integrity of the data and the accuracy of the data analysis. All authors were responsible for the conception and design as well as the analysis and interpretation of data, and the drafting and critical revision of the manuscript.

\section{KARGER}

Fax +4161306 1234

E-Mail karger@karger.ch

www.karger.com (c) 2009 S. Karger AG, Basel

Accessible online at: www.karger.com/ger
Xin-Qi Dong, MD

Rush Institute for Health Aging

1645 West Jackson, Suite 675

Chicago, IL 60612 (USA)

Tel. +1 312942 3350, Fax +1 312942 2861, E-Mail xinqi_dong@ @ush.edu 


\section{Introduction}

Elder self-neglect is an important public health issue that occurs across all sociodemographic groups in the US. Evidence suggests that elder self-neglect has an annual incidence of approximately 1.2 million cases within the US $[1,2]$, and is associated with an increased risk of morbidity and mortality $[3,4]$. A recent commentary in the Journal of the American Medical Association called for rigorous research on self-neglect in the general population [5]. Title XX of the Social Security Act, passed in 1974, mandates states to develop and maintain protective services agencies for vulnerable older adults. In 2004, the US spent nearly USD 500 million on these agencies [5], of which elder self-neglect is the situation most commonly reported. However, our existing knowledge about elder self-neglect in the general population has mostly relied on case studies and case reports to the social service agencies [6]. Although such reports make an invaluable contribution to the field, more comprehensive, systematic and scientifically rigorous studies are needed, so that the problem can be more precisely defined, better solutions developed and appropriate policy established. This is particularly important because recent evidence suggests that reports of elder self-neglect to social services agencies are on the rise [7]. Moreover, as our aging population is rapidly increasing in size, elder self-neglect will likely become an even more pervasive public health issue.

The National Centers on Elder Abuse defines self-neglect as: '.. the behavior of an elderly person that threatens his/her own health and safety. Self-neglect generally manifests itself in an older person as a refusal or failure to provide himself/herself with adequate food, water, clothing, shelter, personal hygiene, medication (when indicated), and safety precautions' [2]. There have been a number of conceptual frameworks postulated for the syndrome of self-neglect $[6,8-10]$. Although there is no uniform consensus on the precise mechanism of self-neglect, the common elements often include poverty, medical comorbidities, depression, cognitive impairment, physical disability, lack of social network and social support. Dyer et al [8] hypothesized that increased burden of medical comorbidities compounded by worsening depression and nutritional deficiencies may lead to physical disability. In addition, physical disability combined with poverty and lack of social network increases the risk of social isolation and lack of ability for self-protection, leading to the syndrome of elder self-neglect.

Currently, there are significant limitations to our understanding of self-neglect and a paucity of population- based studies to better understand this public health issue. We are aware of only 1 population-based cohort that has been used to understand this issue [11, 12]. Furthermore, self-neglect has been difficult to study, in part because self-neglect cases include a wide spectrum of severity, from very mild to extremely severe. Self-neglect, like many other geriatric syndromes, manifest along a continuum of severity, rather than in 2 discrete categories [13]. However, most of our current understanding of elder self-neglect has been derived from studies using categorical terms ('self-neglect yes' and 'self-neglect no') [6], which has further hindered insights into the full continuum of self-neglect severity. We are not aware of any population-based studies that have examined the characteristics of elder self-neglect along the continuum of its severity.

Our cross-sectional study examined the sociodemographic, health-related and psychosocial characteristics associated with elder self-neglect within the context of an epidemiological study, the Chicago Health and Aging Project (CHAP). In addition, we examined the independent association of social network and social support with the risk of elder self-neglect in the same population.

\section{Methods}

\section{Setting}

The CHAP study is a study of the residents of 3 adjacent neighborhoods on the south side of Chicago: Morgan Park, Washington Heights and Beverly. More in-depth details of the CHAP study design have been previously published [14, 15].

Of the 7,813 age-eligible residents identified through the complete census of these 3 community areas in 1993, 6,158 (78.9\%) were enrolled for the baseline population interview. Data collection occurred in cycles, each lasting 3 years, with each cycle ending as the succeeding cycle began. Each cycle consisted of an inperson interview of all subjects in their homes. As of the third cycle in 2000, the CHAP started to enroll successive age cohorts, consisting of community residents who had turned 65 years of age since the inception of the study. Members of these 'successive age cohorts' have the same pattern of data collection, and their data were combined with the original cohort in the proposed analyses. As of 2005, 9,056 subjects had participated in the CHAP study.

\section{Subjects}

Of the 9,056 CHAP participants who had an in-person interview, a subset was reported between 1993 and 2005 to the Chicago Department on Aging (CDOA) for elder self-neglect ( $\mathrm{n}=$ 1,812 ). The CHAP study invited all age-eligible ( $\geq 65$ years or older) residents of these communities to participate, and none were excluded due to degree of cognitive impairment or physical disability. Enrollment interviews for the 9,056 were conducted using 
standardized survey methods that assessed health history, health behavior and psychosocial characteristics of all 9,056 participants. Informed consent was obtained, and the study was approved by the Institutional Review Board at the Rush University Medical Center in Chicago.

\section{Independent Variable: Self-Neglect}

Reporting of Self-Neglect

Elder self-neglect case reports in Chicago can come from a variety of sources, including health care and legal professionals, community faith-based organizations, city workers (e.g. postal workers, utility workers), family members, community members, concerned neighbors or friends, or any other agency that may have contact with community seniors. Currently, there are no mandatory reporting requirements for elder self-neglect, and these reports were from voluntary reporters. These cases are reported to the CDOA, and then an in-home assessment takes place, which includes acquisition of basic demographic information and assessment of self-neglect severity of the elderly person to identify specific services that may be offered by the CDOA.

\section{Assessment of Self-Neglect Severity}

The continuum of self-neglect in this study was assessed based entirely on cases reported to the CDOA $(n=1,812)$. CDOA case workers assess unmet needs in the domains of personal hygiene and grooming, household and environmental hazards, health needs, and overall home safety concerns. Elder self-neglect severity is rated by the CDOA based on concerns for unmet personal health and safety needs. A total of 15 items were used to rate the degree of unmet needs and each of the items were scored on a scale of $0-3$, with higher numbers indicating greater danger to health and safety. The details of this measure have been previously described [16]. The maximum cumulative score was 45 points, with a higher score indicating greater self-neglect severity. In order to convey clinical significance, self-neglect severity was presented in 4 categories: unconfirmed, mild, moderate and severe. Available information from the social services agency report [17] showed that the self-neglect measure was tested using the $\kappa$ statistic algorithm [18], and all variables had inter-rater reliability coefficients $>0.70$. In addition, the internal consistencies of the items are high, with Cronbach's $\alpha=0.95$. Both face validity and content validity were evaluated using qualitative data from case managers and agency administrators. In addition, external validity of the measure was assessed, and was shown to predict higher health care utilization [17].

\section{Matching CDOA Data to CHAP Data}

We began with total of 9,056 CHAP subjects, and matched this dataset with the CDOA dataset from 1993 through 2005. Self-neglect data had been collected by the CDOA, and had already been obtained for 1993 through 2005 . We completed the data-matching process, and found a total of 1,812 CHAP subjects who had been reported to the CDOA. We used date of birth, sex, race, exact home address, zip codes and the home phone number of each client to perform the match. The matching process was performed twice to ensure accuracy. Self-neglect severity information has been integrated efficiently into the parent CHAP study to ensure the availability of the extensive background and health information collected as part of the CHAP study.
Sociodemographic, Health-Related and Psychosocial Variables

All of the sociodemographic, health-related and psychosocial variables were uniformly ascertained through the parent CHAP study. Sociodemographic variables used in analyses included age (years), sex (men or women), race (African-American or White), levels of education (years) and level of income (income categories: 1 = USD 0-4,999; 2 = USD 5,000-9,999; 3 = USD 10,000-14,999; $4=$ USD 15,000-19,999; $5=$ USD 20,000-24,999; 6 = USD 25,00029,$999 ; 7=$ USD $30,000-34,999 ; 8=$ USD 35,000-49,999; $9=$ USD $50,000-74,999 ; 10=$ USD 75,000 and over). Self-reported medical condition details were collected for hypertension, diabetes mellitus, stroke, heart disease, cancer and thyroid disease. Cognitive function was assessed using the Mini-Mental State Examination (MMSE) [19], which is a widely used 30-item measure of dementia severity. Physical function was assessed using the Katz Activities of Daily Living (ADL) scale, which measures limitations in an individual's ability to perform basic self-care tasks [20]. It consists of 6 items, and an ADL score is created by adding the individual items (range 0-6). Depressive symptoms were assessed by using the modified version [21] of the Center for Epidemiologic Studies Depression Scale (CESD; range: 0-10) [22] used in the Established Populations for Epidemiologic Studies of the Elderly study (EPESE). Social network was assessed by asking questions about the number of children, relatives and friends, according to the distance between their domicile and the elder's domicile and the frequency that they saw the elder, as was done in the EPESE study [23]. Social engagement was assessed by asking how often the subjects participated in social activities outside of the house: religious activities, museums, libraries and senior centers. BMI was calculated by dividing the measured weight in kilograms by the square of the measured height in meters.

\section{Analytic Approach}

Statistical tests ( $\chi^{2}$ or $t$ test) were performed to compare the 1,812 subjects with reports of elder self-neglect with the 7,244 subjects without reports of elder self-neglect. This was done across all the sociodemographic, health-related and psychosocial variables previously mentioned. In addition, all these comparisons between the reported and unreported groups were adjusted for age and sex. Furthermore, logistical regression was used to examine the independent association of social network and social engagement with risk of self-neglect. In the first model (model A), we included the core variables of age, sex, race, education and income. In the following models (models B-F), we added 5 additional confounders (medical conditions, depression, cognitive impairment, physical disability and nutritional status) one at a time to examine the association of social network and social engagement with self-neglect. Finally, in order to convey clinical significance, self-neglect severity variables were further categorized into 4 groups: unconfirmed, mild, moderate and severe selfneglect. We compared sociodemographic, health-related and psychosocial variables across these groups. Raw numbers, means, percentiles and standard deviations (SD) are reported for all of the sociodemographic and health-related measures for each of the groups; $p$ values were calculated to determine if there was a trend for any sociodemographic, health-related or psychosocial variable to monotonically increase with increasing elder self-neglect severity. Analyses were carried out in SAS 8 (SAS Institute, Cary, N.C., USA). 
Table 1. Characteristics of reported elder self-neglect in a community-dwelling population

\begin{tabular}{|c|c|c|c|c|}
\hline & $\begin{array}{l}\text { Reported } \\
(\mathrm{n}=1,812)\end{array}$ & $\begin{array}{l}\text { Unreported } \\
(\mathrm{n}=7,244)\end{array}$ & $\begin{array}{l}\text { Age- and sex-adjusted } \\
\text { OR and } 95 \% \text { CI }\end{array}$ & $\mathrm{p}$ \\
\hline Age, (mean $\pm S D)$, years & $77.7 \pm 7.7$ & $73.3 \pm 7.2$ & $1.07(1.07-1.08)$ & 0.001 \\
\hline $65-69$ & $291(16.3)$ & $2,925(41.5)$ & 1.0 & \\
\hline $70-74$ & $431(24.1)$ & $1,842(26.1)$ & $2.35(2.01-2.76)$ & 0.001 \\
\hline $75-79$ & $409(22.8)$ & $951(13.5)$ & $4.31(3.65-5.09)$ & 0.001 \\
\hline Women & $1,211(66.8)$ & $4,422(61.0)$ & $1.15(1.03-1.29)$ & 0.013 \\
\hline White & $236(13.1)$ & $1,808(25.0)$ & 1.0 & \\
\hline African-American & $1,576(86.9)$ & $5,436(75.0)$ & $3.66(3.13-4.29)$ & 0.001 \\
\hline Education, years & $11.1 \pm 3.4$ & $11.7 \pm 3.5$ & $1.02(1.01-1.04)$ & 0.001 \\
\hline \multicolumn{5}{|l|}{ Education period (years) } \\
\hline Income category & $3.7 \pm 2.0$ & $4.1 \pm 2.2$ & $1.01(0.97-1.04)$ & 0.001 \\
\hline \multicolumn{5}{|l|}{ Income category } \\
\hline$\geq 7$ & $149(11.9)$ & $600(16.4)$ & 1.0 & \\
\hline $5-6$ & $218(17.4)$ & $659(18.0)$ & $1.25(0.98-1.60)$ & 0.071 \\
\hline $3-4$ & $474(37.9)$ & $1,349(36.9)$ & $1.09(0.88-1.37)$ & 0.460 \\
\hline $1-2$ & $410(32.8)$ & $1,046(28.6)$ & $0.96(0.76-1.21)$ & 0.718 \\
\hline Medical conditions & $1.6 \pm 1.1$ & $1.1 \pm 1.0$ & $1.52(1.44-1.60)$ & 0.001 \\
\hline \multicolumn{5}{|l|}{ Specific medical conditions } \\
\hline No heart disease & $1,388(76.6)$ & $6,231(86.1)$ & 1.0 & \\
\hline Heart disease & $378(20.9)$ & $1,013(13.9)$ & $1.57(1.37-1.79)$ & 0.001 \\
\hline No stroke & $1,398(77.2)$ & $6,487(89.5)$ & 1.0 & \\
\hline Stroke & $369(20.4)$ & $757(10.5)$ & $2.07(1.80-2.39)$ & 0.001 \\
\hline Diabetes mellitus & $279(15.4)$ & $612(8.4)$ & $2.13(1.82-2.49)$ & 0.001 \\
\hline CESD & $2.4 \pm 2.4$ & $1.7 \pm 2.1$ & $1.11(1.08-1.13)$ & 0.001 \\
\hline \multicolumn{5}{|l|}{ CESD distribution } \\
\hline 0: lowest & $460(25.4)$ & $2,695(37.2)$ & 1.0 & \\
\hline $1-2$ & $583(32.2)$ & $2,528(34.9)$ & $1.27(1.11-1.46)$ & 0.001 \\
\hline $3-4$ & $319(17.6)$ & $987(13.6)$ & $1.68(1.43-1.99)$ & 0.001 \\
\hline$\geq 5$ & $450(24.8)$ & $1,034(14.3)$ & $2.03(1.74-2.37)$ & 0.001 \\
\hline MMSE & $23.4 \pm 6.8$ & $25.5 \pm 5.5$ & $1.02(1.02-1.03)$ & 0.001 \\
\hline \multicolumn{5}{|l|}{ MMSE quartiles } \\
\hline 4: highest & $326(20.0)$ & $2,283(32.8)$ & 1.0 & \\
\hline 3 & $517(31.7)$ & $2,448(35.2)$ & $1.34(1.15-1.56)$ & 0.001 \\
\hline 2 & $222(13.6)$ & $743(10.7)$ & $1.75(1.44-2.13)$ & 0.001 \\
\hline 1: lowest & $564(34.6)$ & $1,480(21.3)$ & $1.79(1.53-2.11)$ & 0.001 \\
\hline Katz disability & $1.1 \pm 1.8$ & $0.4 \pm 1.2$ & $1.21(1.17-1.26)$ & 0.001 \\
\hline \multicolumn{5}{|l|}{ Katz disability distribution } \\
\hline 0 & $1,127(64.1)$ & $6,151(85.2)$ & 1.0 & \\
\hline 1 & $182(10.4)$ & $359(4.9)$ & $2.10(1.73-2.56)$ & 0.001 \\
\hline 2 & $129(7.3)$ & $223(3.1)$ & $2.20(1.74-2.79)$ & 0.001 \\
\hline 3 or more & $321(18.3)$ & $488(6.7)$ & $2.51(2.13-2.96)$ & 0.001 \\
\hline
\end{tabular}


Table 1 (continued)

\begin{tabular}{|c|c|c|c|c|}
\hline BMI & $27.4 \pm 6.7$ & $28.0 \pm 6.2$ & $1.02(1.01-1.03)$ & 0.002 \\
\hline \multicolumn{5}{|l|}{ BMI quartiles } \\
\hline 4: highest & $392(24.8)$ & $1,709(25.9)$ & 1.0 & \\
\hline 3 & $274(17.4)$ & $1,326(20.1)$ & $1.25(1.05-1.49)$ & 0.012 \\
\hline 2 & $439(27.8)$ & $2,054(31.1)$ & $1.35(1.15-1.58)$ & 0.001 \\
\hline Social network & $6.0 \pm 5.3$ & $6.9 \pm 5.9$ & $1.02(1.01-1.03)$ & 0.001 \\
\hline \multicolumn{5}{|c|}{ Social network quartiles } \\
\hline 4: highest & $397(23.1)$ & $1,965(27.7)$ & 1.0 & \\
\hline 3 & $196(11.4)$ & $939(13.2)$ & $1.03(0.85-1.24)$ & 0.788 \\
\hline 2 & $673(39.1)$ & $2,750(38.8)$ & $1.11(0.97-1.28)$ & 0.137 \\
\hline 1: lowest & $454(26.4)$ & $1,441(20.3)$ & $1.19(1.02-1.39)$ & 0.027 \\
\hline \multicolumn{5}{|c|}{ Social engagement quartiles } \\
\hline 2 & $673(38.5)$ & $2,757(38.2)$ & $1.46(1.25-1.70)$ & 0.001 \\
\hline 1: lowest & $553(31.6)$ & $1,315(18.2)$ & $2.18(1.85-2.58)$ & 0.001 \\
\hline
\end{tabular}

\section{Results}

\section{Characteristics of Elder Self-Neglect}

Of the 9,056 subjects in the CHAP cohort, 1,812 subjects were reported to the CDOA and 7,244 subjects were not reported. The mean age for the reported group was $77.7 \pm 7.7$ years; for the unreported group this was 73.3 \pm 7.2 years $(\mathrm{p}<0.001$; table 1$)$. The reported group compared to the unreported group had a significantly greater proportion of women (66.8 vs. $61.0 \%, \mathrm{p}<0.001)$, more African-Americans ( 86.9 vs. $75 \%, \mathrm{p}<0.001$ ), and lower levels of education $(11.1 \pm 3.4$ vs. $11.7 \pm 3.5$ years, $\mathrm{p}<$ $0.001)$ and income categories ( $3.7 \pm 2.0$ vs. $4.1 \pm 2.2, \mathrm{p}<$ $0.001)$. In addition, categorization of age and education indicates that there is a greater risk of self-neglect among those older subgroups and those with lower levels of education.

The mean numbers of chronic medical conditions were $1.6 \pm 1.1$ for the reported group and $1.1 \pm 1.0$ for the unreported group $(\mathrm{p}<0.001)$. In particular, the study found that those with self-reported history of heart disease (OR 1.57, 95\% CI 1.37-1.79), stroke (OR 2.07, 95\% CI 1.80-2.39), cancer (OR 1.36, 95\% CI 1.19-1.55), hypertension (OR 1.97, 95\% CI 1.76-2.21), thyroid disease (OR 1.23, 95\% CI 1.01-1.50) and diabetes mellitus (OR 2.13,
95\% CI 1.82-2.49) were more likely to be reported for elder self-neglect (table 1). With respect to cognitive and physical function, there were also significant differences between those with self-neglect and those without selfneglect. In addition, categorization of cognitive function and physical function indicate that lower levels of cognitive function and physical function were associated with greater risk of elder self-neglect (table 1).

Differences in psychosocial factors between the reported and unreported groups were analyzed (table 1). Depressive symptoms (CESD) were higher in the reported group $(2.4 \pm 2.4)$ than in the unreported group (1.7 $\pm 2.1, \mathrm{p}<0.001)$. Social network and social engagement levels for the reported groups were significantly lower compared to unreported group.

\section{Associations of Social Network and Social Engagement} with Elder Self-Neglect

After adjusting for the core variables (table 2, model A), lower levels of social network were associated with increased risk of self-neglect (OR 1.02, 95\% CI 1.01-1.04). After addition of medical comorbidities to the core model, the association did not change (model B). In the subsequent models (models $\mathrm{C}-\mathrm{F}$ ), after addition of CESD, MMSE, Katz ADL and BMI, the association of social net- 
Table 2. Association of social network with reported self-neglect

\begin{tabular}{|c|c|c|c|c|c|c|}
\hline & Model A & Model B & Model C & Model D & Model E & Model F \\
\hline Age (centered at 75 years) & $1.12(1.10-1.13)$ & $1.12(1.11-1.13)$ & $1.12(1.11-1.13)$ & $1.12(1.11-1.13)$ & $1.12(1.10-1.13)$ & $1.12(1.11-1.14)$ \\
\hline Sex (men) & $0.90(0.77-1.06)$ & $1.01(0.86-1.18)$ & $1.02(0.87-1.20)$ & $0.97(0.82-1.15)$ & $0.99(0.84-1.18)$ & $0.99(1.11-1.14)$ \\
\hline Race (African-American) & $3.30(2.69-4.06)$ & $3.12(2.53-3.85)$ & $3.17(2.56-3.93)$ & $3.01(2.42-3.75)$ & $3.02(2.42-3.76)$ & $2.98(2.37-3.74)$ \\
\hline Education (centered at 12 years) & $1.03(1.01-1.06)$ & $1.02(1.00-1.05)$ & $1.03(1.00-1.05)$ & $1.03(1.00-1.05)$ & $1.02(0.99-1.05)$ & $1.02(0.99-1.05)$ \\
\hline Income & $1.05(1.01-1.09)$ & $1.05(1.01-1.09)$ & $1.05(1.01-1.09)$ & $1.06(1.02-1.10)$ & $1.06(1.02-1.11)$ & $1.06(1.02-1.11)$ \\
\hline Medical comorbidity & & $1.59(1.48-1.69)$ & $1.57(1.47-1.68)$ & $1.56(1.45-1.67)$ & $1.52(1.41-1.63)$ & $1.51(1.40-1.63)$ \\
\hline CESD & & & $1.04(1.01-1.07)$ & $1.03(0.99-1.06)$ & $1.01(0.97-1.05)$ & $1.01(0.97-1.05)$ \\
\hline MMSE & & & & $0.99(0.97-1.00)$ & $1.00(0.99-1.02)$ & $0.99(0.97-1.01)$ \\
\hline Katz impairment & & & & & $1.16(1.09-1.24)$ & $1.19(1.12-1.29)$ \\
\hline BMI & & & & & & $1.01(0.99-1.02)$ \\
\hline Social network & $1.02(1.01-1.04)$ & $1.02(1.01-1.04)$ & $1.02(1.01-1.04)$ & $1.02(1.01-1.04)$ & $1.02(1.01-1.04)$ & $1.02(1.01-1.04)$ \\
\hline
\end{tabular}

Data presented as OR with 95\% CI in parentheses. Social networks are modeled from higher to lower levels.

Table 3. Association of social engagement with reported self-neglect

\begin{tabular}{|c|c|c|c|c|c|c|}
\hline & Model A & Model B & Model C & Model D & Model E & Model F \\
\hline Age (centered at 75 years) & $1.11(1.10-1.12)$ & $1.11(1.10-1.13)$ & $1.12(1.11-1.13)$ & $1.12(1.11-1.13)$ & $1.12(1.10-1.13)$ & $1.13(1.11-1.14)$ \\
\hline Sex (men) & $0.85(0.73-0.99)$ & $0.95(0.81-1.12)$ & $0.97(0.82-1.14)$ & $0.93(0.78-1.09)$ & $0.95(0.80-1.13)$ & $0.94(0.79-1.13)$ \\
\hline Education (centered at 12 years) & $1.05(1.03-1.07)$ & $1.04(1.02-1.06)$ & $1.04(1.02-1.06)$ & $1.04(1.01-1.07)$ & $1.03(1.01-1.06)$ & $1.04(1.01-1.06)$ \\
\hline Income & $1.07(1.02-1.11)$ & $1.07(1.03-1.11)$ & $1.07(1.03-1.11)$ & $1.07(1.03-1.12)$ & $1.07(1.03-1.12)$ & $1.07(1.03-1.12)$ \\
\hline Medical comorbidity & & $1.54(1.44-1.65)$ & $1.53(1.43-1.64)$ & $1.53(1.42-1.64)$ & $1.50(1.39-1.61)$ & $1.49(1.38-1.61)$ \\
\hline Katz disability & & & & & $1.12(1.05-1.19)$ & $1.15(1.07-1.24)$ \\
\hline BMI & & & & & & $1.01(0.99-1.03)$ \\
\hline Social engagement & $1.22(1.16-1.28)$ & $1.20(1.14-1.25)$ & $1.19(1.13-1.25)$ & $1.19(1.12-1.25)$ & $1.16(1.10-1.23)$ & $1.15(1.09-1.22)$ \\
\hline
\end{tabular}

Data presented as OR with 95\% CI in parentheses. Social engagements are modeled from higher to lower levels.

work and elder self-neglect remained significant. With respect to social engagement, after adjusting for core variables (table 3, model A), lower levels of social engagement were associated with increased risk of self-neglect (OR 1.22, 95\% CI 1.16-1.28). After addition of medical comorbidities, CESD, MMSE, Katz ADL and BMI variables (model F), lower levels of social engagement remained a significant risk factor for elder self-neglect (OR $1.15,95 \%$ CI 1.09-1.22).

\section{Characteristics Associated with Greater Self-Neglect Severity}

The study also examined these sociodemographic characteristics along the continuum of self-neglect severity categories within each reported group (table 4). Of the 1,812 subjects reported for elder self-neglect, there were
$377(20.8 \%)$ subjects with unconfirmed self-neglect, 338 (18.7\%) subjects with mild self-neglect, 1,002 (55.3\%) subjects with moderate self-neglect and 95 (5.2\%) subjects with severe self-neglect. There was a statistically significant trend towards older age, a greater proportion of women, and African-Americans with a higher self-neglect severity score. In addition, there was a significant trend toward a higher total number of medical conditions as self-neglect severity increased. In particular, the study noted that the self-reported proportions of heart disease, stroke and hypertension were higher as self-neglect severity scores increased. Furthermore, there was a significant trend towards lower levels of cognitive function and physical function with greater degrees of self-neglect severity. Finally, when these psychosocial variables were correlated with increasing severities of elder self-neglect, 
Table 4. Characteristics of elder self-neglect across levels of severity in the CHAP

\begin{tabular}{|c|c|c|c|c|c|}
\hline & $\begin{array}{l}\text { Unconfirmed } \\
(\mathrm{n}=377)\end{array}$ & $\begin{array}{l}\text { Mild } \\
(\mathrm{n}=338)\end{array}$ & $\begin{array}{l}\text { Moderate } \\
(n=1,002)\end{array}$ & $\begin{array}{l}\text { Severe } \\
(n=95)\end{array}$ & $\mathrm{p}$ \\
\hline Age, years & $76.6 \pm 7.6$ & $77.2 \pm 7.6$ & $78.2 \pm 7.6$ & $79.3 \pm 9.0$ & 0.001 \\
\hline Women & $229(60.7)$ & $206(60.9)$ & $723(72.2)$ & $53(55.8)$ & 0.001 \\
\hline African-American & $331(87.8)$ & $283(83.7)$ & $884(88.2)$ & $78(82.1)$ & 0.008 \\
\hline Education, years & $11.1 \pm 3.3$ & $11.3 \pm 3.5$ & $10.9 \pm 3.4$ & $11.3 \pm 3.4$ & 0.58 \\
\hline \multicolumn{6}{|c|}{ Specific medical conditions } \\
\hline Heart disease & $73(19.4)$ & $53(15.7)$ & $234(23.4)$ & $18(18.9)$ & 0.01 \\
\hline Stroke & $68(18.0)$ & $51(15.1)$ & $222(22.2)$ & $28(29.5)$ & 0.002 \\
\hline Hypertension & $241(63.9)$ & $211(62.4)$ & $672(67.1)$ & $51(53.7)$ & 0.007 \\
\hline Thyroid disease & $25(6.6)$ & $28(8.3)$ & $94(9.4)$ & $5(5.3)$ & 0.29 \\
\hline Diabetes mellitus & $54(14.3)$ & $54(15.9)$ & $161(16.1)$ & $10(10.5)$ & 0.42 \\
\hline Social network & $6.3 \pm 5.2$ & $5.7 \pm 4.9$ & $6.0 \pm 5.4$ & $5.7 \pm 5.6$ & 0.37 \\
\hline Social engagement & $1.7 \pm 1.6$ & $1.7 \pm 1.5$ & $1.5 \pm 1.5$ & $1.3 \pm 1.6$ & 0.02 \\
\hline
\end{tabular}

Data presented as means $\pm \mathrm{SD}$ or $\mathrm{n}(\%)$.

there were no significant trends for CESD or social network measures, but there was a significant trend for lower levels of social engagement measures.

\section{Discussions}

In a population-based cohort of older people from a geographically defined community, this study found that there are significant differences in sociodemographic, health-related and psychosocial variables between those reported for elder self-neglect and those not reported. In addition, the study found that lower levels of social network and social engagement were independently associated with increased risk of elder self-neglect. Furthermore, the study found that, among the subjects reported for elder self-neglect, there was a significant trend for sociodemographic, health-related and psychosocial variables along the continuum of self-neglect severity.

These findings are consistent with data from case studies and case reports, which found that older age, female gender, lower education and lower income were common variables among those reported for elder self-neglect [2426]. They are also consistent with studies that suggested increasing medical comorbidities and lower psychosocial function are frequently seen in reported cases of elder selfneglect [27-31]. Recently, Dyer et al. [8] described 538 elder self-neglect cases referred by the social services agency for comprehensive geriatric assessment. Common characteristics of elder self-neglect cases were: older age, women and lower levels of psychosocial function.

Our findings appear to support the conceptual framework by Dyer et al. [8]. Our present study specifically tested 2 of the key factors preceding the syndrome of self-neglect: social network and social engagement. Under the framework of Dyer et al. [8], medical comorbidities, depression, cognitive impairment and nutritional deficiencies all contribute to physical disability. In our multivariate analyses, we adjusted for these factors, but this did not significantly alter our study findings. In addition, Dyer et al. [8] considered extrinsic issues, such as lower levels of socioeconomic status, to potentially exacerbate the lack of social network and social engagement. In our present study, even after we considered the levels of education and income, lower levels of social network and social engagement remained independently associated with self-neglect. While our study provided evidence supporting the aforementioned conceptual framework, future longitudinal studies of these factors are needed to confirm this conceptual framework. 
Only 1 study used a population-based cohort to understand issues of elder self-neglect. Lachs et al. [11] used a similar approach to this study to match datasets of the Connecticut Social Services Agency's records with the EPESE study. Of the 2,812 community-dwelling adults aged 65 years and older in the New Haven EPESE cohort, dataset matching found a total of 202 reports of elder selfneglect. From this data linkage, the study found that older age, being men, lower income, medical comorbidities and psychological impairment were associated with elder self-neglect [12]. The difference in our findings, suggesting women were more commonly reported, remains unclear. Dataset matching for the EPESE cohort was from the 1980s, and it is conceivable that demographic changes in the aging population might have contributed to the differences. In addition, there could be local and regional variables in the aging population that were not accounted for.

The present study of the CHAP cohort now expands the understanding of elder self-neglect in this field, while complementing the EPESE study of elder self-neglect in a number of different ways. First, the CHAP study sample is of a larger size $(n=9,056)$ of the community-dwelling cohort population, and dataset matching found 1,812 subjects with self-neglect reported to the social services agency. Second, this study is the first to characterize the continuum of elder self-neglect severity and to examine the sociodemographic, health-related and psychosocial characteristics across the continuum of elder self-neglect severity. Furthermore, our study suggests that AfricanAmericans are significantly more likely to be reported for elder self-neglect in this urban biracial community, and that there is a significant trend for higher proportion of African-Americans with higher degrees of self-neglect severity. The underlying mechanism for these findings needs further investigation. Our findings could be subjected to reporting bias to the social services agency. In addition, there were relatively more African-Americans in the CHAP study, which could potentially account for the differences. Furthermore, we considered whether the racial findings were a marker for lower levels of socioeconomic status. However, adjusting for levels of education and income did not significantly change our findings.

Although the proposed study has the very substantial strengths of being geographically defined, populationbased and of a large sample size, it also has limitations.

First, elder self-neglect is under-reported, and although the rate of under-reporting is unknown, there are most likely CHAP cohort members who have been selfneglectful over time and who were not reported to the
CDOA. This would have underestimated the occurrence of self-neglect. However, the influence of this underestimation of missing additional self-neglect not reported to the CDOA will likely result in a conservative estimate in our findings.

Second, the measurement of self-neglect severity has been designed for practical and administrative use within the social services agency, and not for research purposes where it would have been subjected to uniform methods of data collection. This non-uniformity can cause variability in the measurement of self-neglect severity. Nevertheless, because there has been a paucity of population-based studies, we have had to rely on assessment and validation by the social service agencies, such as the CDOA, in our study.

Third, this was a cross-sectional study of elder self-neglect within the context of a population-based study, and we could not describe the temporal relations of these findings. Further explorations of such temporal relations are now needed to better understand associations of the sociodemographic, health-related and psychosocial variables with elder self-neglect. Nevertheless, this study provides a unique window into a topic of significant clinical relevance, and lays the groundwork for future studies of elder self-neglect.

Fourth, there are other potential factors associated with self-neglect that have not been considered in this study. The study did not have a precise measure of executive dysfunction or assessment of decision-making capacity, both of which have been postulated to be important elements leading to self-neglect. In addition, the study did not have specific indicators of self-neglect to further explore the specific phenotypes of self-neglect and its associated factors. Prior work by McDermott [32] has also suggested the value of understanding specific behaviors of self-neglect. However, we believe that our present findings will set the groundwork for future studies to rigorously investigate these issues.

Fifth, the clinical relevance of the self-neglect severity needs further exploration. In our study, the severity of selfneglect was assessed by the social services agency, and the effects of incremental increases in the self-neglect severity scale remain unclear. Future work is needed to examine the predictive validities of greater levels of self-neglect severity, especially with respect to its relationship to adverse health outcomes. However, our study is the first to provide population-based data on the syndrome of elder self-neglect across the continuum of severity, and will set the foundation for future studies to examine the health consequences along the continuum of self-neglect severity. 
Even when considering these limitations, this study is the largest epidemiological study to examine the wide range of sociodemographic, health-related and psychosocial characteristics of reported elder self-neglect and self-neglect severity within the context of a populationbased study. In addition, our study closely examined the role of social network and social engagement, and found that lower levels of these factors are independently associated with increased risk of elder self-neglect, even after considering a wide range of possible confounders. These findings provide further supportive evidence toward the unpinning of our conceptual framework for self-neglect. Furthermore, dataset matching of the CHAP and the CDOA provides a novel opportunity to explore this extremely difficult area of research in a racially/ethnically and socioeconomically diverse community with comprehensive and uniform measurement of the relevant variables.

Our findings highlight not only important differences between reported and non-reported elder self-neglect across a number of sociodemographic, health-related and psychosocial factors, but also that there is a significant trend for these differences along the continuum of elder self-neglect severity. As in the case of many other geriatric syndromes that present along a continuum rather than in categorical terms, our study suggests that similar consideration should be given when approaching the issue of elder self-neglect. A better understanding of differential risk and protective factors along the continuum of elder self-neglect severity is needed for future work toward the development of targeted strategies for self-neglect prevention methods.
This study has potential implications not only for health care professionals, but also for the practice and policy communities in the assessment, treatment and prevention strategies along the continuum of elder selfneglect. Health care professionals who work with older adults should pay special attention to those with multiple medical comorbidities, depressive symptoms, poor nutritional status, and those with lower levels of cognitive and physical function, who might be at an increased risk of elder self-neglect. In particular, health care professionals should vigilantly monitor the social network and social engagement of frail elders, who may especially be at higher risk of self-neglect. Social services agency should be aware of the health-related and psychosocial functions of those with self-neglect, and understand that lower levels of health status and psychosocial well-being are likely to be associated with greater severities of self-neglect. Multidisciplinary efforts are needed to devise targeted detection, intervention and prevention strategies for elder selfneglect in order to improve health and well-being.

\section{Acknowledgments}

The authors wish to thank Ms. Ann Marie Lane for community development and oversight of project coordination, Ms. Michelle Bos, Ms. Holly Hadden, Mr. Flavio LaMorticella and Ms. Jennifer Tarpey for coordination of the study. We further thank ZhaoTai Cui, MS, and Todd Beck, MS, for statistical programming; George Dombrowski, MS, for data management support. This work was supported by National Institute on Aging grant AG11101, Paul B. Beeson Career Development Award in Aging (K23 AG030944), The Starr Foundation, John A. Hartford Foundation and The Atlantic Philanthropies.

\section{References}

1 National Research Council: Elder Mistreatment: Abuse, Neglect and Exploitation in an Aging America. Washington, National Academies Press, 2003.

2 National Center on Elder Abuse: NCEA: the basics. http://www.ncea.aoa.gov/ncearoot/ Main_Site/pdf/publication/FinalStatistics050331.pdf.

3 Lachs MS, Williams CS, O’Brien S, Pillemer KA, Charlson ME: The mortality of elder mistreatment. JAMA 1998;280:428-432.

4 Dong X: Medical implications of elder abuse and neglect. Clin Geriatr Med 2005;21:293313.

5 Dyer CB, Pickens S, Burnett J: Vulnerable elders: when it is no longer safe to live alone. JAMA 2007;298:1448-1450.

\footnotetext{
6 Pavlou MP, Lachs MS: Could self-neglect in older adults be a geriatric syndrome? J Am Geriatr Soc 2006;54:831-842.

7 Teaster PB: A response to abuse of vulnerable adults: the 2000 survey of State Adult Protective Service. http://www.ncea.aoa.gov/ ncearoot/Main_Site/pdf/research/apsreport030703.pdf.

8 Dyer CB, Goodwin JS, Pickens-Pace S, Burnett J, Kelly PA: Self-neglect among the elderly: a model based on more than 500 patients seen by a geriatric medicine team. Am J Public Health 2007;97:1671-1676.

9 Orem DE: Nursing: Concepts of Practice, ed 4. St Louis, Mosby, 1991.

10 Choi NG, Kim J, Asseff J: Self-neglect and neglect of vulnerable older adults: reexamination of etiology. J Gerontol Soc Work 2009; 52:171-187.

11 Lachs MS, Berkman L, Fulmer T, Horwitz RI: A prospective community-based pilot study of risk factors for the investigation of elder mistreatment. J Am Geriatr Soc 1994; 42:169-173.

12 Abrams RC, Lachs M, McAvay G, Keohane DJ, Bruce ML: Predictors of self-neglect in community-dwelling elders. Am J Psychiatry 2002;159:1724-1730.

13 Mendes de Leon CF: Aging and the elapse of time: a comment on the analysis of change. J Gerontol B Psychol Sci Soc Sci 2007;62:S198S202.
} 
14 Bienias JL, Beckett LA, Bennett DA, Wilson RS, Evans DA: Design of the Chicago Health and Aging Project (CHAP). J Alzheimers Dis 2003;5:349-355.

15 Evans DA, Bennett DA, Wilson RS, Bienias JL, Morris MC, Scherr PA, et al: Incidence of Alzheimer disease in a biracial urban community: relation to apolipoprotein $\mathrm{E}$ allele status. Arch Neurol 2003;60:185-189.

16 Dong X, Mendes de Leon CF, Evans DA: Is greater self-neglect severity associated with lower levels of physical function? J Aging Health 2009;21:596-610.

17 Illinois Department on Aging: Determination of Need Revision Final Report Volume I. Springfield, Illinois Department on Aging, 1989.

18 Fleiss JL: Measuring nominal scale agreement among many raters. Psychol Bull 1971; 76:378-382.

19 Folstein MF, Folstein SE, McHugh PR: 'MiniMental State': a practical method for grading the cognitive state of patients for the clinician. J Psychiatr Res 1975;12:189-198.
20 Katz S, Akpom CA: A measure of primary sociobiological functions. Int J Health Serv 1976;6:493-508.

21 Kohout FJ, Berkman LF, Evans DA, Cornoni-Huntley J: Two shorter forms of the CESD (Center for Epidemiological Studies Depression) depression symptoms index. Aging Health 1993;5:179-193.

22 Radloff L: The CES-D Scale: a self-report depression scale for research in the general population. Appl Psychol Meas 1977;1:385401.

23 Cornoni-Huntley J, Brock DB, Ostfeld A, Taylor JO, Wallace RB: Established Populations for Epidemiological Studies of the Elderly Resource Data Book (Rep. No. NIH Publication No. 86-2443). Washington, US Department of Health and Human Services, 1986.

24 Cornwall JV: Filth, squalor and lice: self neglect in the elderly. Nurs Mirror 1981;153: 48-49.
25 Granick R, Zeman FD: The aged recluse - an exploratory study with particular reference to community responsibility. J Chronic Dis 1960;12:639-653.

26 O'Rawe AM: Nursing care study: self-neglect - a challenge for nursing. Nurs Times 1982; 78:1932-1936.

27 Smith SM, Mathews Oliver SA, Zwart SR, Kala G, Kelly PA, Goodwin JS, et al: Nutritional status is altered in the self-neglecting elderly. J Nutr 2006;136:2534-2541.

28 Longres JF: Self-Neglect among the elderly. J Elder Abuse Neglect 1995;7:87-105.

29 Orrell MW, Sahakian BJ, Bergmann K: Selfneglect and frontal lobe dysfunction. $\mathrm{Br} \mathrm{J}$ Psychiatry 1989;155:101-105.

30 Lauder W: A survey of self-neglect in patients living in the community. J Clin Nurs 1999;8:95-102.

31 Reyes-Ortiz CA: Diogenes syndrome: the self-neglect elderly. Compr Ther 2001;27: 117-121.

$32 \mathrm{McDermott}$ S: The devil is in the details: selfneglect in Australia. J Elder Abuse Negl 2008;20:231-250. 